\title{
Obesity, adipokines, and prostate cancer (Review)
}

\author{
JACQUES BAILLARGEON and DAVID P. ROSE \\ Center for Epidemiology and Biostatistics, Department of Pediatrics, University of Texas Health Science Center \\ at San Antonio, 7703 Floyd Curl Drive, San Antonio, TX 78229-3900, USA
}

Received September 6, 2005; Accepted October 17, 2005

\begin{abstract}
Prostate cancer, the third most common cancer in men worldwide, varies substantially according to geographic region and race/ethnicity. Obesity and associated endocrine variation are foremost among the risk factors that may underlie these regional and ethnic differences. The association between obesity and prostate cancer incidence is complex and has yielded inconsistent results. Studies that have linked obesity with prostate cancer mortality, advanced stage disease, and higher grade Gleason score, however, have produced more consistent findings, indicating that obesity may not necessarily increase the risk of prostate cancer, but may promote it once established. Additionally, metabolic syndrome, which includes disturbed glucose metabolism and insulin bioactivity, may also be associated with prostate carcinogenesis. Adipokines, defined as biologically active polypeptides produced by adipose tissue, have been linked with a number of carcinogenic mechanisms, including angiogenesis, cell proliferation, metastasis, and alterations in sex-steroid hormone levels. A number of emerging studies have implicated the role of adipokines in prostate carcinogenesis. This review explores the specific roles of several adipokines as putative mediating factors between obesity and prostate cancer with particular attention to leptin, interleukin-6 (IL-6), heparin-binding epidermal growth factorlike growth factor (HB-EGF), vascular endothelial growth factor (VEGF) and adiponectin.
\end{abstract}

\section{Contents}

1. Introduction

2. Obesity and the metabolic syndrome

3. Adipose tissue-derived cytokines

4. Leptin and prostate cancer

Correspondence to: Dr Jacques Baillargeon, Center for Epidemiology and Biostatistics, Department of Pediatrics, University of Texas Health Science Center at San Antonio, 7703 Floyd Curl Drive, San Antonio, TX 78229-3900, USA

E-mail: baillargeon@uthscsa.edu

Key words: prostate cancer, obesity, body mass index, adipokines, cytokines, leptin, adiponectin
5. IL-6 and HB-EGF and prostate cancer

6. Special relationships of adiponectin

7. Angiogenesis in prostate cancer

8. Commentary

\section{Introduction}

Prostate cancer is the third most common cancer in men worldwide and occurs most commonly in the United States and Canada, and northwestern Europe, but is uncommon in Asian countries and South America (1). An epidemiologic study of 12 countries of the European Union shows a clear north-south gradient in prostate cancer incidence and mortality, which has persisted over time, with particularly high figures for England and Wales, and low rates in Italy, Spain, and Portugal (2). Although Asian men have the lowest incidence and mortality rates of prostate cancer worldwide, these have been showing a rapid increase over the past 20-30 years, possibly a consequence, of a shift in dietary practices towards a more western pattern, and the associated increase in obesity (3). Obesity, adiposity and the associated endocrine factors may contribute substantially to such geographic and ethnic differences in prostate cancer incidence worldwide and will be the focus of this review (1).

During the earlier stages of the disease, most prostate cancers are dependent for their growth on stimulation by androgenic steroids, and tumor regression can be obtained by surgical and medical suppression of androgen action $(4,5)$. However, a point is eventually reached when a proportion of the cancer cells are no longer dependent on androgens and renewed progression takes place. This situation occurs in part when tumor cells emerge which both synthesize and secrete polypeptide growth factors such as epidermal growth factor, transforming growth factor- $\alpha$, and insulin-like growth factor-1 (IGF-1), and possess the corresponding cell membrane receptors: the resulting autocrine stimulation is typical of androgen-independent prostate cancer cells (6).

In addition to inducing phenotypic changes in the prostate cancer cell, the immediate microenvironment provided by the host tissues may play an important role in the growth and metastasis of prostate cancers (5). There are multiple modes of action for this host-tumor cell relationship; in this review we will develop the concept that one such mechanism arises from the metabolic consequences of obesity and the metabolic syndrome, and in particular the endocrine and paracrine activities of cytokines synthesized by adipose tissue. 


\section{Obesity and the metabolic syndrome}

Obesity and body fat distribution. Studies assessing the association between obesity and prostate cancer have yielded inconsistent results. Several investigations found an increased risk of prostate cancer among obese and overweight men (7-12), including a large prospective study from Sweden which involved 134,000 construction workers (10). Other studies, however, indicated little or no association (13-17), among which were two of prospective design with 9,000 and 47,781 men, respectively $(13,15)$.

More consistent results have been obtained for patients with established disease, where obesity was found to be predictive of a poor prognosis $(10,18-20)$, and to be associated with higher tumor grade and stage $(11,19-25)$, indicative of more aggressive cancer, and with more advanced disease at the time of diagnosis, defined by invasion through the prostatic capsule, involvement of adjacent tissues and lymph glands and, perhaps, distant metastases $(9,22,25)$. A large study by Kane et al (26) involving 2,952 prostate cancer patients showed a positive correlation between BMI values in those categorized as being overweight to very obese $\left(25 \mathrm{~kg} / \mathrm{m}^{2}\right.$ or more) and tumors with a poor prognosis as based on the calculated tumor volume and the pretreatment prostatic specific antigen level. These observations suggest that the relationship between obesity and prostate cancer is the result of its biological effects in promoting an aggressive phenotype rather than the transformation of the prostatic epithelium per se.

However, in addition to obesity which is present at the time of prostate cancer diagnosis, a number of investigations have examined the significance of body weight earlier in life on subsequent prostate carcinogenesis. A study from Italy found a positive association between prostate cancer risk and a high BMI at age 30 years (27), and the Netherlands Cohort Study (28) gave results which showed the BMI at 20 years of age to be positively related to risk. Another prospective study, from Scotland, with a mean follow-up of 41 years, found that there was an increased risk for subsequent prostate cancer death for men in the highest BMI category at age 20-22 years, few of whom were obese (29). In contrast to these results, Robinson et al (30) performed a case-control study of prostate cancer in African-American and white American men in relation to the presence of obesity when they were less than 30 years of age and found evidence of a reduced risk in those who had a BMI of $30 \mathrm{~kg} / \mathrm{m}^{2}$ or higher.

The distribution of body fat, as opposed to adiposity assessed by the BMI, has been studied extensively in breast cancer; most investigators used the ratio of the waist to hip circumference (WHR) for this purpose, and the majority, but not all, concluded that a high WHR, indicative of upper body obesity, is associated with an increase in postmenopausal breast cancer and, perhaps, with a poor prognosis (31). Although the amount of data available for evaluation is limited, upper body or visceral obesity has also been found to correlate with increased prostate cancer risk. In a case-control study from China (17) a high WHR was related to an excess risk; interestingly, there was no relationship between risk and the BMI in this study. Actually, while providing some useful information in epidemiological studies, the WHR is a relatively crude method of assessing body fat distribution because it does not distinguish between deep abdominal or visceral fat and subcutaneous fat deposits. Von Hafe et al (12) used computerized tomography to measure the abdominal fat directly in a casecontrol study, and showed that the prostate cancer patients had a higher mean visceral fat area and visceral to subcutaneous fat area ratio than controls: the calculated prostate cancer risk associated with these indicators of visceral adiposity had odds ratios of 4.6 and 6.0 , respectively.

Metabolic syndrome. The metabolic (or insulin resistance) syndrome is characterized by a cluster of biochemical abnormalities and associated clinical conditions, not all of which are necessarily present in a given case, but which include disturbed glucose metabolism and insulin bioactivity resulting in hyperglycemia and hyperinsulinemia, dyslipidemia (hypertriglyceridemia and low levels of HDL cholesterol), hypertension, and type 2 diabetes (32). Central obesity is often present, but the syndrome does occur in its absence; lean individuals exhibit a wide range of insulin sensitivity, and may have levels as low as those of obese insulin-resistant subjects (33). The mechanisms underlying this syndrome are not completely understood, but insulin resistance associated with obesity, sedentary lifestyle, energy intake, and genetic predisposition are part of the etiology $(32,33)$. Since prostate cancer has been linked to many of the component endocrine characteristics of metabolic syndrome, investigators have recently begun assessing its association with prostate cancer. The metabolic syndrome is a common clinical condition in countries with western dietary patterns and a high incidence of obesity; in the United States its prevalence in the adult population has been estimated to be approximately $25 \%$ (32).

The case-control study of Chinese men performed by Hsing et al (17), which showed that a high WHR, but not the BMI, was positively associated with prostate cancer risk, was extended to include an examination of several serum constituents, including the insulin concentration (34). After adjustment for the BMI and WHR there was a highly significant association between higher serum insulin levels and increased risk of prostate cancer. However, there was also an interaction between the WHR and the serum insulin. Men in the highest tertiles of both WHR and insulin had 8.55 times the prostate cancer risk of men in the two lower tertiles; those with the lowest tertile of WHR, but the highest tertile of insulin had 4.30 times the risk. In a further study by these same investigators (35), the homeostasis model assessment was used to evaluate insulin resistance in prostate cancer patients and controls; the results showed that the men in the highest tertile of insulin resistance were at an increased cancer risk, and conversely, a high degree of insulin sensitivity was associated with reduced risk. Again, there was an interaction between high WHR and insulin resistance. Laukkanen et al (36), in a prospective study of prostate cancer in Finland, reported that men with metabolic syndrome were nearly two times more likely to develop prostaste cancer than those without. This association was stronger in overweight men with a BMI $>27 \mathrm{~kg} / \mathrm{m}^{2}$ (adjusted relative risk, 3.0; 95\% CI 1.2-3.7) than in lighter men (adjusted relative risk, 1.8; 95\% CI 0.7-4.7). These findings were not attenuated by adjusting for potential lifestyle factors such as alcohol consumption, smoking, physical fitness, or a number of dietary factors. 
Features of the metabolic syndrome have also been associated with the occurrence of larger tumors at the time of prostate cancer diagnosis. In the study by Hammarsten and Hogstedt (37) patients with later stage prostate cancer were found to have relatively high plasma insulin levels, and more likely than those with early tumors to be hypertensive and dyslipidemic, with elevated serum triglycerides and reduced HDL-cholesterol levels. Also, they were more obese, with higher WHRs, and, particularly the large waist circumference which is so often an anthropometric feature of the metabolic syndrome.

Mechanisms. The progression of prostatic carcinogenesis is believed to involve epithelial-mesenchymal/stromal interaction which takes place with the participation of both testosterone and estradiol (38), but the precise roles of these two classes of steroid hormones is not entirely clear. However, estrogens alone, or in conjunction with androgens do induce aberrant prostate growth and neoplastic transformation (39).

Obesity might facilitate prostate carcinogenesis and progression during the phase of hormone dependence through its enhancement of estrogen biosynthesis. This occurs due to an increase in the activity of aromatase which is located in the accumulated adipose tissue; there is an age-related and adiposity-related increase in the aromatization of testosterone to estradiol (40); alternatively, the loss of testosterone could be expected to exert a suppressive effect on prostate cancer development. The situation is rendered even more complex by the possibility that in the presence of the metabolic syndrome the increase in insulin bioactivity might produce up-regulation of testosterone production by insulin (41); in addition, the bioavailability of the androgen is enhanced by an obesity and insulin-related reduction in sex hormone-binding globulin (SHBG) synthesis $(41,42)$.

In recent years there has been increasing recognition that adipose tissue functions as an endocrine and paracrine organ, and exerts widespread biological effects by the production of cytokine-like polypeptide factors. Several of these have been studied for their contribution to prostate cancer development and progression, both during the androgen-dependent and androgen-independent phases of growth and metastasis.

\section{Adipose tissue-derived cytokines}

A variety of biologically active factors are secreted by the fat storage cells (the adipocytes) and supporting stromal cells, and by other cell types, particularly macrophages, which infiltrate the adipose tissue and accumulate in increased numbers in association with obesity (43). The hormone-like polypeptides produced in the adipose tissue are termed adipokines. Those synthesized specifically by the adipocytes were first designated as adipocytokines by Matsuzawa et al (44). Several, including leptin, heparin-binding epidermal growth factor-like growth factor (HB-EGF), interleukin-6 (IL-6), vascular endothelial growth factor (VEGF), and adiponectin, are becoming increasingly recognized for their multiple effects on the biological behavior of tumor cells. Adipokines circulate in the blood, and, like steroid hormones, they can exert their biological actions on target cells by classical ligand-receptor endocrine mechanisms. In addition, like the inflammatory cytokines, they can operate at the local level through paracrine and autocrine pathways.

The plasma concentrations of leptin $(45,46)$, HB-EGF (47), and IL-6 (48) are all elevated in obese men. Serum VEGF concentrations have been reported to be positively correlated with the visceral fat mass (49) and VEGF stimulates expansion of the capillary network in fat tissue which is essential for increasing adiposity $(50,51)$. In contrast, plasma adiponectin levels decrease with increasing adiposity $(52,53)$. A number of the adipokines are involved in the regulation of insulin activity, and their production is altered in the metabolic syndrome. Leptin can disrupt insulin signaling (54); plasma leptin and insulin show a positive correlation, and hyperleptinemia, as well as hyperinsulinemia, is a biological feature of both type 2 diabetes and the metabolic syndrome $(55,56)$. Conversely, adiponectin promotes insulin sensitivity in target tissues, and opposes the development of type 2 diabetes (57); hypoadiponectinemia is associated with the metabolic syndrome (58). The biological properties of leptin suggest its involvement in breast cancer cell growth, invasion, and metastasis, and in tumor-related neovascularization or angiogenesis $(31,59)$.

\section{Leptin and prostate cancer}

Epidemiological studies and circulating leptin concentrations. Equivocal results have been obtained from the investigation of plasma leptin levels in prostate cancer patients. Hsing et al (34), in their case-control study of Chinese men, found that although those with serum insulin levels in the highest tertile had an increased prostate cancer risk, the association between serum leptin concentrations and risk was not statistically significant.

Stattin et al (60) originally reported that the results from a nested case-control analysis showed that moderately, but curiously not markedly, elevated plasma leptin concentrations were related to an increased risk of prostate cancer. However, a second study by this same group failed to confirm the relationship (61), and neither has the work of other investigators $(62,63)$. Despite the lack of any convincing evidence that high plasma leptin levels are related to prostate cancer risk, there are indications from some (64-66), but not all (67), studies that the same abnormality is predictive of high grade disease and more advanced tumors. Certainly, the results of investigations of leptin and prostate cancer cell biology support such a relationship.

Prostate cancer cell biology. Leptin receptor protein was detected by immunohistochemical staining with an antibody reactive to the long and short isoforms in normal human prostatic cells, intraepithelial neoplasia, and prostate cancer epithelium (60) and the mRNAs for both forms of the receptor were demonstrated in the androgen-independent DU145 and PC-3 human prostate cancer cell lines (68). In cell culture experiments, exogenous leptin stimulated the growth of these two lines (68-70), but the androgen-dependent LNCaP prostate cancer cell line, although it possesses the two leptin receptor isoforms, showed no mitogenic response to the ligand (69).

The proliferative response of DU145 and PC-3 prostate cancer cells to leptin was shown to involve phosphatidyl- 
inositol 3-kinase (PI3K) and mitogen-activated protein kinase (MAPK) activation (68), and the participation of activated c-Jun NH2-terminal kinase (JNK); the pharmacological inhibition of JNK blocked the proliferative response to leptin (69). It is of particular interest to the present discussion that JNK has been shown to be elevated in animal models of obesity, and to induce insulin resistance $(71,72)$. Yang et al (73) showed in a series of human prostate cancer cell lines that there was a strong correlation between the extent of their growth enhancement in the presence of high serum supplementation in vitro and serum-inducible JNK activity. Lin et al (74) demonstrated that the PI3K pathway is also critical for the survival of androgen-dependent prostate cancer cells by showing that apoptosis of LNCaP cells occurred rapidly in the presence of a PI3K inhibitor, an antiproliferative effect which was attenuated by another adipocytokine, HB-EGF.

\section{IL-6 and HB-EGF and prostate cancer}

The adipose tissue is a major production site of IL-6 $(75,76)$, although infiltrating macrophages and stromal cells produce most of the IL-6 arising in adipose tissue and only about $10 \%$ is synthesized by the adipocytes (76). There is a positive correlation between the serum IL-6 concentration and the BMI $(48,75)$ and the circulating levels are elevated in obesity and insulin resistance (76-78).

The serum IL-6 levels are also increased in some prostate cancer patients, when they are associated particularly with a loss of androgen dependence $(79,80)$, the presence of metastatic disease (81-83), and reduced survival time $(84,85)$. Although these observations are consistent with an IL-6mediated adverse effect of obesity on prostate cancer outcome, and this cytokine does stimulate the growth of human prostate cancer cell lines in vitro $(86,87)$, the synthesis and secretion of the polypeptide by the tumor cells themselves suggests that autocrine stimulation may also contribute to IL-6mediated growth (86-89). Okamoto et al (86) reported that the androgen-dependent LNCaP cell line was much more responsive to culture medium containing added IL-6 than the DU145 and PC-3 cell lines, whereas only the two androgenindependent lines secreted significant endogenously produced levels of the cytokine. The inference from these results is that IL-6, most likely derived from adipose sources, is primarily a paracrine, and perhaps endocrine, growth factor for androgendependent prostate cancer cells but that it assumes an autocrine function of the tumor cells themselves as part of the emergence of androgen independence.

Heparin-binding epidermal growth factor-like growth factor is produced at multiple sites including human adipose tissue. There is an increase in HB-EGF mRNA expression by adipose tissue in obese mice (47), and a positive correlation exists between plasma HB-EGF concentrations and the BMI in humans (90). Like IL-6, exogenous HB-EGF stimulates the growth of cultured human prostate cancer cell lines $(91,92)$ and is produced by the tumor cells, so providing the potential for significant autocrine mitogenic activity (91). The expression of HB-EGF was found to be considerably greater in cell lines that were androgen-independent $(92,93)$ suggesting, as in the case of IL-6, an adipokine-related mechanism for escape of prostate cancer from androgen dependence.

\section{Special relationships of adiponectin}

Adiponectin is a $30-\mathrm{kDa}$ collagen-like plasma protein which is synthesized exclusively in adipocytes (94). One of the most abundant adipocytokines, it circulates in the blood at a concentration which amounts to $0.05 \%$ of the total serum proteins (94). The plasma adiponectin levels, like those of leptin, are higher in women than men $(57,95,96)$. Nishizawa et al (95) found in a group of Japanese men that the plasma adiponectin concentration was $34 \%$ lower than in women; in parallel experimental studies they showed that castration produced a significant elevation in plasma adiponectin in mature male mice, while the administration of testosterone to both these androgen-deficient animals and intact mice caused a reduction in the secretion of adiponectin from adipose tissue and in the plasma concentration of the adipocytokine.

There are a number of situations other than their opposing actions on insulin signaling, where adiponectin has been shown to have effects which are clearly antagonistic to those produced by leptin. Adiponectin can accelerate the process of apoptosis in hematopoietic cells, for which leptin is mitogenic (97); it induces apoptotic activity by down-regulating $\mathrm{Bcl}-2$ expression (98). Also, at least under some circumstances it was found to have a similar effect on vascular endothelial cell growth by activating the caspase cascade (99), which contrasts with the $\mathrm{Bcl}$-2-inducing, antiapoptotic activity of leptin on these cells (100).

These opposing effects of adiponectin and leptin on various aspects of metabolism and cell biology suggest that, in contrast to leptin, adiponectin may possess anticancer properties which are lost in clinical situations associated with hypoadiponectinemia. In support of this proposition are reports that subnormal plasma concentrations of adiponectin are related to increased risks of carcinoma of the breast $(101,102)$, and endometrium $(103,104)$, and in men but apparently not in women, cancer of the colon (105). One of the studies of breast cancer also showed that patients with low adiponectin levels were more likely to have tumors which were large and of high histologic grade (102). A small case-control study performed in Turkey by Goktas et al (106) has now extended the relationship between hypoadiponectinemia and cancer to include carcinoma of the prostate. Plasma adiponectin levels were significantly lower in a group of 30 prostate cancer patients than in 41 patients with benign prostatic hyperplasia, and 36 healthy controls. Further, the adiponectin concentrations were inversely correlated with the tumor grade and disease stage. It is important to a discussion of prostate cancer and insulin resistance that although obese men were excluded from this study, and there were no significant differences in the BMI values between the three groups, the plasma insulin levels were higher, and insulin resistance as indicated by the homeostasis model assessment method was greater in the cancer patients, and particularly so in those whose disease had spread beyond the confines of the gland itself.

There have been no published studies to determine if adiponectin has a direct effect, inhibitory or otherwise, on prostate, breast, endometrial, or colon cancer cell proliferation, but Yokota et al (98) did report that it suppressed the growth of myelocyte lines and induced apoptosis in myelomonocytic leukemia cell lines. Also, when infused into highly vascularized 
mouse fibrosarcomas, adiponectin caused suppression of tumor growth, but here the mechanism was most likely an antiangiogenic effect (99).

\section{Angiogenesis in prostate cancer}

Angiogenesis is the process by which new blood vessels are formed from preexisting vasculature. Once neoplastic transformation has taken place, and carcinoma in situ has formed, angiogenesis-mediated cancer progression may occur by a process of tumor cell proliferation, vascularization of the tumor mass, local invasion, and metastasis to sites remote from the primary tumor (107-109). In clinical studies of prostate cancer, angiogenesis correlated with disease stage and the presence of metastases (110-112), and was shown to occur in those intraepithelial neoplasms (111) and latent carcinomas (113) which exhibited potential for progression to invasive disease.

A high degree of microvessel density, indicative of active angiogenesis, and a relatively high expression of VEGF, were found concurrently in high grade, potentially aggressive, human prostate cancer tissues (112,114-116). Moreover, VEGF expression was further enhanced in tumors that had extended beyond the capsule of the gland, and so gained access to the surrounding adipose tissue $(114,115)$. Increased Plasma VEGF concentrations have also been reported in patients with metastatic prostate cancer compared with those in patients with localized disease and healthy controls (117).

Vascular endothelial cell proliferation and migration in vitro and the complete process of angiogenesis in vivo are stimulated not only by VEGF, but also by leptin $(118,119$, reviewed in ref. 31). Heparin-binding EGF-like growth factor is also a potent promoter of angiogenesis; it does not stimulate vascular endothelial cell proliferation directly, but it is an inducer of VEGF expression $(120,121)$, and stimulates endothelial cell migration $(120,121)$, the production of proteolytic enzymes which are essential for the movement of the cells, and their organization into vascular tubes (120-122). Finally, HB-EGF was shown to be angiogenic in in vivo models $(120,121)$.

The physiological and pathological significance of IL-6 as a stimulator of angiogenesis is currently undergoing vigorous investigation. Although it was reported to have only weak stimulatory effects on the migration of vascular endothelial cells and their formation of tubular systems in vitro, and not to stimulate angiogenesis in the rabbit corneal model (123) more recent experiments showed that IL-6 can induce VEGF expression and promote angiogenesis in a gastric carcinoma model (124), and also stimulate the transcriptional up-regulation of VEGF and VEGF secretion in glioblastoma cells (125). It also induced angiogenesis indirectly by the induction of bFGF expression in an in vitro model (126).

Thus, all three of the adipokines discussed in this review whose production from adipose tissue is directly correlated with the BMI exert positive effects on the angiogenic process. Transformed prostatic cells which are initially restricted to the gland itself by the surrounding capsule come under the influence of these adipose tissue-derived angiogenic factors when they invade the retropubic fat pad which will enhance their capacity for further growth and metastasis to the regional lymph nodes and distant sites.
In keeping with its general opposition to the biological activities of leptin, Brakenhielm et al (99) reported that adiponectin possesses antiangiogenic properties. In their experiments they showed that, in contrast to leptin and VEGF, adiponectin inhibited the growth of microvascular (capillary) endothelial cells, and their capacity for migration in vitro. Furthermore, it suppressed the stimulatory effects of bFGF on microvascular endothelial cell proliferation, and of VEGF on cell migration. In vivo, adiponectin inhibited angiogenesis in both the mouse corneal and the chick chorioallantoic membrane models. As noted earlier, Brakenhielm and colleagues also showed that the infusion of adiponectin into highly vascularized mouse fibrosarcomas produced suppression of tumor growth, with an associated reduction in angiogenic activity.

\section{Commentary}

The relationships between obesity, androgens and leptin are complex, and may contribute to the inconsistencies seen in the reports of studies of obesity and prostate cancer risk. Obesity in men is associated with a reduction in both the plasma total and the free, non-SHBG-bound and biologically active, testosterone levels $(40,127)$; Isidori et al (128) found that this decrease in the free testosterone could occur even when there was a concomitant reduction in the plasma SHBG concentration. Obesity in boys is associated with delayed pubertal development, and an obesity-related state of relative hypoandrogenism may explain the finding by Giovannucci et al (15) from their large prospective study that although the adult BMI was not related to prostate cancer risk or stage at diagnosis, obese boys were more likely to exhibit a reduced risk of having advanced prostate cancer when the disease was diagnosed in later life.

A somewhat similar result from a case-control study was reported by Robinson et al (30), although here obesity was assessed in young adults aged 20-29 years and preadolescent boys. An inverse relationship was found between the BMI and later risk of advanced prostate cancer which was evident in preadolescence, but most pronounced between the ages of 20 and 29 years. It should be noted that if reduced testosterone levels in early life are responsible for producing changes in the prostate gland which mitigate against the subsequent emergence of prostate cancer with an aggressive phenotype, they do so in the presence of an increase in the plasma leptin. However, it may be relevant that, as we saw earlier, leptin only activated JNK and stimulated the growth of androgenindependent human prostate cancer cell lines; there was no effect of leptin on the testosterone responsive $\mathrm{LNCaP}$ prostate cancer line $(68,69)$. Thus, we can speculate that the behavior of premalignant or cancerous prostate cells in response to leptin is determined by their androgen dependence and that this, in turn, may contribute to the positive and negative effects reported from different studies of the influence of obesity on prostate cancer.

One additional but related factor may be the degree of obesity present in the study population. Robinson et al (30) referenced 7 studies of body size in young adult males and their subsequent risk of prostate cancer and advanced disease; none showed a reduced risk in those with higher BMI values, but rather there was either no effect or a slight increase in 
risk. However, as in the case of the young men referred to earlier in the study by Okasha et al (29), and in contrast to those examined by Giovannucci et al (15) and Robinson et al (30) none of the study subjects included individuals with BMI levels in the obesity range, and in consequence any suppressive effect on the plasma testosterone concentrations may have been minimal. In support of this conclusion, it is noteworthy that Robinson et al (30) also found a slight increase in the risk of advanced prostate cancer in their subjects with BMI values in the 25-29 range, i.e. overweight but not obese.

The increased risk of prostate cancer and of higher grade and stage which Goktas et al (106) reported in association with reduced plasma adiponectin concentrations was not related to higher BMI values and none of the subjects included in this small case-control study were obese. However, it is of special interest that in addition to the subnormal adiponectin levels, progression to high prostate cancer grade was associated with biochemical evidence of sequential increases in insulin resistance and related hyperinsulinemia. This result is consistent with other reports that insulin resistance and other features of the metabolic syndrome are related to increased prostate cancer risk and advanced disease (34-37). Further investigations should be designed to distinguish between a causative role for insulin resistance per se in prostate carcinogenesis and expression of the metastatic phenotype, and a primary, specific, effect of hypoadiponectinemia on prostate (and breast and endometrial) cancer biology.

The role of an adipokine as a classical hormone in the growth and metastasis of prostate cancer is best supported by the available evidence in the case of adiponectin. This is the one adipose tissue-derived polypeptide of the five discussed in this review where the circulating concentrations have been shown to correlate with both cancer risk and metastatic potential; moreover, the epidemiological support for a negative effect of adiponectin on tumorigenesis contrasts with the results of experimental studies of leptin (129), HB-EGF (91), and IL-6 (86) which demonstrated positive paracrine and autocrine activities of these growth factors when they are produced not by surrounding adipose tissue, but by the tumor cells themselves.

Studies are now needed to determine the biological significance of the adipokines when they are produced locally by adipose tissue surrounding the prostate cancer cells. The anatomical situation differs from that in breast cancer because the tumor cells are separated from ready access to a mass of adipose tissue until they have breached the prostatic capsule, whereas breast cancer cells are surrounded by the adipocytes and adipose stromal cells which are an integral part of the breast tissue. Once extension beyond the capsule occurs, leptin, HB-EGF and IL-6 may all act on the prostate cancer cells to enhance their further growth and invasion, either directly or by acting in concert with adipocyte-derived VEGF to stimulate tumor-supporting angiogenesis.

\section{References}

1. Quinn M and Babb P: Patterns and trends in prostate cancer incidence, survival, prevalence and mortality. Part 1: international comparisons. BJU Int 90: 162-173, 2002.

2. Vercelli M, Quaglia A, Marani E and Parodi S: Prostate cancer incidence and mortality trends among elderly and adult Europeans. Crit Rev Oncol Hematol 35: 133-144, 2000.
3. Pu YS, Chiang HS, Lin CC, Huang CY, Huang KH and Chen J: Changing trends of prostate cancer in Asia. Aging Male 7: $120-132,2004$.

4. Denis LJ and Griffiths K: Endocrine treatment in prostate cancer. Semin Surg Oncol 18: 52-74, 2000.

5. Arnold JT and Isaacs JT: Mechanisms involved in the progression of androgen-independent prostate cancers: it is not only the cancer cell's fault. Endocr Relat Cancer 9: 61-73, 2002.

6. Connolly JM and Rose DP: Regulation of DU145 human prostate cancer cell proliferation by insulin-like growth factors and its interaction with the epidermal growth factor autocrine loop. Prostate 24: 167-175, 1994.

7. Talamini R, La Vecchia C, Decarli A, Negri E and Franceschi S: Nutrition, social factors and prostatic cancer in a Northern Italian population. Br J Cancer 53: 817-821, 1986.

8. Moller H, Mellemgaard A, Lindvig K and Olsen JH: Obesity and cancer risk: a Danish record-linkage study. Eur J Cancer 30A: 344-350, 1994.

9. Cerhan JR, Torner JC, Lynch CF, et al: Association of smoking, body mass, and physical activity with risk of prostate cancer in the Iowa 65+ Rural Health Study (United States). Cancer Causes Control 8: 229-238, 1997

10. Andersson SO, Wolk A, Bergstrom R, Adami HO, Engholm G, Englund A and Nyren O: Body size and prostate cancer: a 20-year follow-up study among 135006 Swedish construction workers. J Natl Cancer Inst 89: 385-389, 1997.

11. Freedland SJ, Terris MK, Platz EA and Presti JC: Body mass index as a predictor of prostate cancer: development versus detection on biopsy. Urology 66: 108-113, 2005.

12. Von Hafe P, Pina F, Perez A, Tavares M and Barros H: Visceral fat accumulation as a risk factor for prostate cancer. Obes Res 12: 1930-1935, 2004.

13. Jonsson F, Wolk A, Pedersen NL, Lichtenstein P, Terry P, Ahlbom A and Feychting M: Obesity and hormone-dependent tumors: cohort and co-twin control studies based on the Swedish Twin Registry. Int J Cancer 106: 594-599, 2003.

14. Furuya Y, Akimoto S, Akakura K and Ito H: Smoking and obesity in relation to the etiology and disease progression of prostate cancer in Japan. Int J Urol 5: 134-137, 1998.

15. Giovannucci E, Rimm EB, Stampfer MJ, Colditz GA and Willett WC: Height, body weight, and risk of prostate cancer. Cancer Epidemiol Biomarkers Prev 6: 557-563, 1997.

16. Hubbard JS, Rohrmann S, Landis PK, et al: Association of prostate cancer risk with insulin, glucose, and anthropometry in the Baltimore longitudinal study of aging. Urology 63: 253-258, 2004.

17. Hsing AW, Deng J, Sesterhenn IA, et al: Body size and prostate cancer: a population-based case-control study in China. Cancer Epidemiol Biomarkers Prev 9: 1335-1341, 2000.

18. Rodriguez C, Patel AV, Calle EE, Jacobs EJ, Chao A and Thun MJ: Body mass index, height, and prostate cancer mortality in two large cohorts of adult men in the United States. Cancer Epidemiol Biomarkers Prev 10: 345-353, 2001

19. Freedland SJ, Terris MK, Presti JC, et al: Search Database Study Group. Obesity and biochemical outcome following radical prostatectomy for organ confined disease with negative surgical margins. J Urol 172: 520-524, 2004.

20. Amling CL, Riffenburgh RH, Sun L, et al: Pathologic variables and recurrence rates as related to obesity and race in men with prostate cancer undergoing radical prostatectomy. J Clin Oncol 22: 439-445, 2004.

21. Putnam SD, Cerhan JR, Parker AS, Bianchi GD, Wallace RB, Cantor KP and Lynch CF: Lifestyle and anthropometric risk factors for prostate cancer in a cohort of Iowa men. Ann Epidemiol 10: 361-369, 2000.

22. Mydlo JH, Tieng NL, Volpe MA, Chaiken R and Kral JG: A pilot study analyzing PSA, serum testosterone, lipid profile, body mass index and race in a small sample of patients with and without carcinoma of the prostate. Prostate Cancer Prostatic Dis 4: 101-105, 2001.

23. Amling CL, Kane CJ, Riffenburgh RH, et al: Relationship between obesity and race in predicting adverse pathologic variables in patients undergoing radical prostatectomy. Urology 58: 723-728, 2001.

24. Rohrmann S, Roberts WW, Walsh PC and Platz EA: Family history of prostate cancer and obesity in relation to high-grade disease and extraprostatic extension in young men with prostate cancer. Prostate 55: 140-146, 2003. 
25. Freedland SJ, Isaacs WB, Mangold LA, et al: Stronger association between obesity and biochemical progression after radical prostatectomy among men treated in the last 10 years. Clin Cancer Res 11: 2883-2888, 2005.

26. Kane CJ, Bassett WW, Sadetsky N, et al: Obesity and prostate cancer clinical risk factors at presentation: data from CAPSURE. J Urol 173: 732-736, 2005.

27. Dal Maso L, Zucchetto A, La Vecchia C, et al: Prostate cancer and body size at different ages: an Italian multicentre casecontrol study. Br J Cancer 90: 2176-2180, 2004.

28. Schuurman AG, Goldbohm RA, Dorant E and van den Brandt PA: Anthropometry in relation to prostate cancer risk in the Netherlands Cohort Study. Am J Epidemiol 151: 541-549, 2000.

29. Okasha M, McCarron P, McEwen J and Smith GD: Body mass index in young adulthood and cancer mortality: a retrospective cohort study. J Epidemiol Community Health 56: 780-784, 2002.

30. Robinson WR, Stevens J, Gammon MD and John EM: Obesity before age 30 years and risk of advanced prostate cancer. Am J Epidemiol 161: 1107-1114, 2005.

31. Rose DP, Komninou D and Stephenson GD: Obesity, adipocytokines, and insulin resistance in breast cancer. Obes Rev 5: 153-165, 2004

32. Ford ES, Giles WH and Dietz WH: Prevalence of the metabolic syndrome among US adults: findings from the third National Health and Nutrition Examination Survey. JAMA 287: 356-359, 2002.

33. Kahn SE, Prigeon RL, Schwartz RS, Fujimoto WY, Knopp RH, Bruzell JD and Porte D: Obesity, body fat distribution, insulin sensitivity and islet beta-cell function as explanations for metabolic diversity. J Nutr 131: S354-S360, 2001.

34. Hsing AW, Chua S Jr, Gao YT, Gentzschein E, Chang L, Deng J and Stanczyk FZ: Prostate cancer risk and serum levels of insulin and leptin: a population-based study. J Natl Cancer Inst 93: 783-789, 2001 .

35. Hsing AW, Gao YT, Chua S Jr, Deng J and Stanczyk FZ: Insulin resistance and prostate cancer risk. J Natl Cancer Inst 95: 67-71, 2003.

36. Laukkanen JA, Laaksonen DE, Niskanen L, Pukkala E, Hakkarainen A and Salonen JT: Metabolic syndrome and the risk of prostate cancer in Finnish men: a population - based study. Cancer Epidemiol Biomarkers Prev 13: 1646-1650, 2004.

37. Hammarsten J and Hogstedt B: Clinical, haemodynamic, anthropometric, metabolic and insulin profile of men with highstage and high-grade clinical prostate cancer. Blood Press 13: 47-55, 2004.

38. Cunha GR, Ricke W, Thomson A, et al: Hormonal, cellular, and molecular regulation of normal and neoplastic prostatic development. J Steroid Biochem Mol Biol 92: 221-236, 2004.

39. Ho SM: Estrogens and antiestrogens: key mediators of prostate carcinogenesis and new therapeutic candidates. J Cell Biochem 91: 491-503, 2004.

40. Vermeulen A, Kaufman JM, Goemaere S and van Pottelberg I: Estradiol in elderly men. Aging Male 5: 98-102, 2002.

41. Pasquali R, Casimirri F, De Iasio R, et al: Insulin regulates testosterone and sex hormone-binding globulin concentrations in adult normal weight and obese men. J Clin Endocrinol Metab 80: 654-658, 1995

42. Lewis JG, Shand BI, Elder PA and Scott RS: Plasma sex hormone-binding globulin rather than corticosteroid-binding globulin is a marker of insulin resistance in obese adult males. Diabetes Obes Metab 6: 259-263, 2004.

43. Weisberg SP, McCann D, Desai M, Rosenbaum M, Leibel RL and Ferrante AW Jr: Obesity is associated with macrophage accumulation in adipose tissue. J Clin Invest 112: 1796-1808, 2003.

44. Matsuzawa Y, Funahashi T and Nakamura T: Molecular mechanism of metabolic syndrome $\mathrm{X}$ : contribution of adipocytokines adipocyte-derived bioactive substances. Ann NY Acad Sci 892: 146-154, 1999.

45. Considine RV, Sinha MK, Heiman ML, et al: Serum immunoreactive-leptin concentrations in normal weight and obese humans. N Engl J Med 334: 292-295, 1996.

46. Ruhl CE and Everhart JE: Leptin concentrations in the United States: relations with demographic and anthropometric measures. Am J Clin Nutr 74: 295-301, 2001.

47. Matsumoto S, Kishida K, Shimomura I, et al: Increased plasma HB-EGF associated with obesity and coronary artery disease. Biochem Biophys Res Commun 292: 781-786, 2002.
48. Khaodhiar L, Ling PR, Blackburn GL and Bistrian BR: Serum levels of interleukin-6 and C-reactive protein correlate with body mass index across the broad range of obesity. J Parenter Enteral Nutr 28: 410-415, 2004.

49. Miyazawa-Hoshimoto S, Takahashi K, Bujo H, Hashimoto N and Saito Y: Elevated serum vascular endothelial growth factor is associated with visceral fat accumulation in human obese subjects. Diabetologia 46: 1483-1488, 2003.

50. Crandall DL, Hausman GJ and Kral JG: A review of the microcirculation of adipose tissue: anatomic, metabolic, and angiogenic perspectives. Microcirculation 4: 211-232, 1997.

51. Neels JG, Thinnes T and Loskutoff DJ: Angiogenesis in an in vivo model of adipose tissue development. FASEB J 18: 983-985, 2004.

52. Arita Y, Kilhara S, Ouchi N, et al: Paradoxical decrease of an adipose-specific-protein, adiponectin, in obesity. Biochem Biophys Res Commun 257: 79-83, 1999.

53. Hotta K, Funahashi T, Arita Y, et al: Plasma concentrations of a novel, adipose-specific protein, adiponectin, in type 2 diabetic patients. Arterioscler Thromb Vasc Biol 20: 1595-1599, 2000.

54. Cohen B, Novick D and Rubinstein M: Modulation of insulin activities by leptin. Science 274: 1185-1188, 1996.

55. Wauters M, Considine RV, Yudkin JS, Peiffer F, De Leeuw I and van Gaal LF: Leptin levels in type 2 diabetes: associations with measures of insulin resistance and insulin secretion. Horm Metab Res 35: 92-96, 2003

56. Leyva F, Godsland IF, Ghatei M, et al: Hyperleptinemia as a component of a metabolic syndrome of cardiovascular risk. Arterioscler Thromb Vasc Biol 18: 928-933, 1998.

57. Duncan BB, Schmidt MI, Pankow JS, et al: Adiponectin and the development of type 2 diabetes. The Atherosclerosis Risk in Communities Study. Diabetes 53: 2473-2478, 2004.

58. Sharma AM and Chetty VT: Obesity, hypertension and insulin resistance. Acta Diabetol 42 (Suppl 1): S3-S8, 2005.

59. Rose DP, Gilhooly EM and Nixon DW: Adverse effects of obesity on breast cancer prognosis, and the biological actions of leptin. Int J Oncol 21: 1285-1292, 2002.

60. Stattin P, Soderberg S, Hallmans G, et al: Leptin is associated with increased prostate cancer risk: a nested case-referent study. J Clin Endocrinol Metab 86: 1341-1345, 2001.

61. Stattin P, Kaaks R, Johansson R, et al: Plasma leptin is not associated with prostate cancer risk. Cancer Epidemiol Biomarkers Prev 12: 474-475, 2003.

62. Lagiou P, Signorello LB, Trichopoulos D, Tzonou A, Trichopoulou A and Mantzoros CS: Leptin in relation to prostate cancer and benign prostatic hyperplasia. Int J Cancer 76: 25-28 1998

63. Nowicki M, Bryc W and Kokot F: Hormonal regulation of appetite and body mass in patients with advanced prostate cancer treated with combined androgen blockade. J Endocrinol Invest 24: 31-36, 2001

64. Chang S, Hursting SD, Contois $\mathrm{JH}$, et al: Leptin and prostate cancer. Prostate 46: 62-67, 2001.

65. Saglam K, Aydur E, Yilmaz M and Goktas S: Leptin influences cellular differentiation and progression in prostate cancer. J Urol 169: 1308-1311, 2003.

66. Ribeiro R, Vasconcelos A, Costa S, et al: Overexpressing leptin genetic polymorphism $(-2548 \mathrm{G} / \mathrm{A})$ is associated with susceptibility to prostate cancer and risk of advanced disease. Prostate 59: 268-274, 2004

67. Freedland SJ, Sokoll LJ, Mangold LA, et al: Serum leptin and pathological findings at the time of radical prostatectomy. J Urol 173: 773-776, 2005

68. Somasundar P, Frankenberry KA, Skinner H, et al: Prostate cancer cell proliferation is influenced by leptin. J Surg Res 118: $71-82,2004$

69. Onuma M, Bub JD, Rummel TL and Iwamoto Y: Prostate cancer cell-adipocyte interaction: leptin mediates androgen-independent prostate cancer cell proliferation through c-Jun NH2-terminal kinase. J Biol Chem 278: 42660-42667, 2003.

70. Somasundar P, Yu AK, Vona-Davis L and McFadden DW: Differential effects of leptin on cancer in vitro. J Surg Res 113: 50-55, 2003

71. Hirosumi J, Tuncman G, Chang L, et al: A central role for JNK in obesity and insulin resistance. Nature 420: 333-336, 2002 .

72. Ozcan U, Cao Q, Yilmaz E, et al: Endoplasmic reticulum stress links obesity, insulin action, and type 2 diabetes. Science 306 : 457-461, 2004. 
73. Yang YM, Bost F, Charbono W, et al: c-Jun NH (2) - terminal kinase mediates proliferation and tumor growth of human prostate carcinoma. Clin Cancer Res 9: 391-401, 2003.

74. Lin J, Adam RM, Santiestevan E and Freeman MR: The phosphatidylinositol 3'-kinase pathway is a dominant growth factor-activated cell survival pathway in $\mathrm{LNCaP}$ human prostate carcinoma cells. Cancer Res 59: 2891-2897, 1999.

75. Mohamed-Ali V, Goodrick S, Rawesh A, et al: Subcutaneous adipose tissue releases interleukin-6, but not tumor necrosis factoralpha, in vivo. J Clin Endocrinol Metab 82: 4196-4200, 1997.

76. Fried SK, Bunkin DA and Greenberg AS: Omental and subcutaneous adipose tissue of obese subjects release interleukin-6: depot difference and regulation by glucocorticoid. J Clin Endocrinol Metab 83: 847-850, 1998.

77. Fernandez-Real JM and Ricart W: Insulin resistance and chronic cardiovascular inflammatory syndrome. Endocr Rev 24: 278-301, 2003.

78. Kern PA, Ranganathan S, Li C, Wood L and Ranganathan G: Adipose tissue tumor necrosis factor and interleukin- 6 expression in human obesity and insulin resistance. Am J Physiol Endocrinol Metab 280: E745-E751, 2001.

79. Drachenberg DE, Elgamal AA, Rowbotham R, Peterson M and Murphy GP: Circulating levels of interleukin-6 in patients with hormone refractory prostate cancer. Prostate 41: 127-133, 1999.

80. Wise GJ, Marella VK, Talluri G and Shirazian D: Cytokine variations in patients with hormone treated prostate cancer. J Urol 164: 722-725, 2000.

81. Akimoto S, Okumura A and Fuse H: Relationship between serum levels of interleukin-6, tumor necrosis factor-alpha and bone turnover markers in prostate cancer patients. Endocr J 45: 183-189, 1998.

82. Adler HL, McCurdy MA, Kattan MW, Timme TL, Scardino PT and Thompson TC: Elevated levels of circulating interleukin-6 and transforming growth factor-beta 1 in patients with metastatic prostatic carcinoma. J Urol 161: 182-187, 1999.

83. Michalaki V, Syrigos K, Charles P and Waxman J: Serum levels of IL-6 and TNF-alpha correlate with clinicopathological features and patient survival in patients with prostate cancer. Br J Cancer 90: 2312-2316, 2004.

84. Nakashima J, Tachibana M, Horiguchi Y, Oya M, Ohigashi T, Asakura $\mathrm{H}$ and Murai M: Serum interleukin 6 as a prognostic factor in patients with prostate cancer. Clin Cancer Res 6: 2702-2706, 2000.

85. George DJ, Halabi S, Shepard TF, Sanford B, Vogelzang NJ, Small EJ and Kantoff PW: The prognostic significance of plasma interleukin-6 levels in patients with metastatic hormone-refractory prostate cancer: results from cancer and leukemia group B 9480 . Clin Cancer Res 11: 1815-1820, 2005.

86. Okamoto M, Lee C and Oyasu R: Interleukin-6 as a paracrine and autocrine growth factor in human prostatic carcinoma cells in vitro. Cancer Res 57: 141-146, 1997.

87. Giri D, Ozen M and Ittmann M: Interleukin-6 is an autocrine growth factor in human prostate cancer. Am J Pathol 159: 2159-2165, 2001.

88. Chung TD, Yu JJ, Spiotto MT, Bartkowski M and Simons JW: Characterization of the role of IL-6 in the progression of prostate cancer. Prostate 38: 199-120, 1999.

89. Hobisch A, Rogatsch H, Hittmair A, et al: Immunohistochemical localization of interleukin- 6 and its receptor in benign, premalignant and malignant prostate tissue. J Pathol 191: 239-244, 2000.

90. Matsuzawa Y, Shimomura I, Kihara S and Funahashi T: Importance of adipocytokines in obesity-related diseases. Horm Res 60 (Suppl 3): 56-59, 2003.

91. Freeman MR, Paul S, Kaefer M, et al: Heparin-binding EGFlike growth factor in the human prostate: synthesis predominantly by interstitial and vascular smooth muscle cells and action as a carcinoma cell mitogen. J Cell Biochem 68: 328-338, 1998.

92. Torring N, Jorgensen PE, Sorensen BS and Nexo E: Increased expression of heparin binding EGF (HB-EGF), amphiregulin, TGF alpha and epiregulin in androgen-independent prostate cancer cell lines. Anticancer Res 20: 91-95, 2000.

93. Adam RM, Kim J, Lin J, Orsola A, Zhuang L, Rice DC and Freeman MR: Heparin-binding epidermal growth factor-like growth factor stimulates androgen-independent prostate tumor growth and antagonizes androgen receptor function. Endocrinology 143: 4599-4608, 2002.

94. Scherer PE, Williams S, Fogliano M, Baldini G and Lodish HF: A novel serum protein similar to Clq, produced exclusively in adipocytes. J Biol Chem 270: 26746-26749, 1995.
95. Nishizawa H, Shimomura I, Kishida K, et al: Androgens decrease plasma adiponectin, an insulin-sensitizing adipocytederived protein. Diabetes 51: 2734-2741, 2002.

96. Cnop M, Havel PJ, Utzschneider KM, et al: Relationship of adiponectin to body fat distribution, insulin sensitivity and plasma lipoproteins: evidence for independent roles of age and sex. Diabetologia 46: 459-469, 2003.

97. Bennett BD, Solar GP, Yuan JQ, Mathias J, Thomas GR and Matthews W: A role for leptin and its cognate receptor in hematopoiesis. Curr Biol 6: 1170-1180, 1996.

98. Yokota T, Oritani K, Takahashi I, et al: Adiponectin, a new member of the family of soluble defense collagens, negatively regulates the growth of myelomonocytic progenitors and the functions of macrophages. Blood 96: 1723-1732, 2000.

99. Brakenhielm E, Veitonmaki N, Cao R, et al: Adiponectininduced antiangiogenesis and antitumor activity involve caspasemediated endothelial cell apoptosis. Proc Natl Acad Sci USA 101: 2476-2481, 2004.

100. Artwohl M, Roden M, Holzenbein T, Freudenthaler A, Waldhausl W and Baumgartner-Parzer SM: Modulation by leptin of proliferation and apoptosis in vascular endothelial cells. Int J Obes Relat Metab Disord 26: 577-580, 2002.

101. Mantzoros C, Petridou E, Dessypris N, et al: Adiponectin and breast cancer risk. J Clin Endocrinol Metab 89: 1102-1107, 2004.

102. Miyoshi Y, Funahashi T, Kihara S, Taguchi T, Tamaki Y, Matsuzawa Y and Noguchi S: Association of serum adiponectin levels with breast cancer risk. Clin Cancer Res 9: 5699-5704, 2003.

103. Dal Maso L, Augustin LS, Karalis A, Talamini R, Franceschi S, Trichopoulos D, Mantzoros CS and La Vecchia C: Circulating adiponectin and endometrial cancer risk. J Clin Endocinol Metab 89: 1160-1163, 2004.

104.Petridou E, Mantzoros C, Dessypris N, et al: Plasma adiponectin concentrations in relation to endometrial cancer: a case-control study in Greece. J Clin Endocrinol Metab 88: 993-997, 2003.

105. Stattin P, Palmqvist R, Soderberg S, et al: Plasma leptin and colorectal cancer risk: a prospective study in Northern Sweden. Oncol Rep 10: 2015-2021, 2003.

106. Goktas S, Yilmaz MI, Caglar K, Sonmez A, Kilic S and Bedir S: Prostate cancer and adiponectin. Urology 65: 1168-1172, 2005.

107. Van Moorselaar RJ and Voest EE: Angiogenesis in prostate cancer: its role in disease progression and possible therapeutic approaches. Mol Cell Endocrinol 197: 239-250, 2002.

108. Lara PN Jr, Twardowski P and Quinn DI: Angiogenesis-targeted therapies in prostate cancer. Clin Prostate Cancer 3: 165-173, 2004.

109. Cox MC, Permenter M and Figg WD: Angiogenesis and prostate cancer: important laboratory and clinical findings. Curr Oncol Rep 7: 215-219, 2005.

110. Wakui S, Furusato M, Itoh T, et al: Tumour angiogenesis in prostatic carcinoma with and without bone marrow metastasis: a morphometric study. J Pathol 168: 257-262, 1992.

111. Brawer MK, Deering RE, Brown M, Preston SD and Bigler SA: Predictors of pathologic stage in prostatic carcinoma. The role of neovascularity. Cancer 73: 678-687, 1994.

112. Stefanou D, Batistatou A, Kamina S, Arkoumani E, Papachristou DJ and Agnantis NJ: Expression of vascular endothelial growth factor (VEGF) and association with microvessel density in benign prostatic hyperplasia and prostate cancer. In Vivo 18: 155-160, 2004.

113. Furusato M, Wakui S, Sasaki H, Ito K and Ushigome S: Tumour angiogenesis in latent prostatic carcinoma. Br J Cancer 70: 1244-1246, 1994.

114. Kuniyasu H, Troncoso P, Johnston D, et al: Relative expression of type IV collagenase, E-cadherin, and vascular endothelial growth factor/vascular permeability factor in prostatectomy specimens distinguishes organ-confined from pathologically advanced prostate cancer. Clin Cancer Res 6: 2295-2308, 2000.

115. Strohmeyer D, Strauss F, Rossing C, et al: Expression of bFGF, VEGF and c-met and their correlation with microvessel density and progression in prostate carcinoma. Anticancer Res 24: 1797-1804, 2004

116. Trojan L, Thomas D, Knoll T, Grobholz R, Alken P and Michel MS: Expression of pro-angiogenic growth factors VEGF, EGF and bFGF and their topographical relation to neovascularisation in prostate cancer. Urol Res 32: 97-103, 2004. 
117. Duque JL, Loughlin KR, Adam RM, Kantoff PW, Zurakowski D and Freeman MR: Plasma levels of vascular endothelial growth factor are increased in patients with metastatic prostate cancer. Urology 54: 523-527, 1999.

118. Sierra-Honigmann MR, Nath AK, Murakami C, et al: Biological action of leptin as an angiogenic factor. Science 281: 1683-1686, 1998.

119. Bouloumie A, Drexler HC, Lafontan M and Busse R: Leptin, the product of $\mathrm{Ob}$ gene, promotes angiogenesis. Circ Res 83: 1059-1066, 1998.

120. Abramovitch R, Neeman M, Reich R, et al: Intercellular communication between vascular smooth muscle and endothelial cells mediated by heparin-binding epidermal growth factor - like growth factor and vascular endothelial growth factor. FEBS Lett 425: 441-447, 1998.

121. Ongusaha PP, Kwak JC, Zwible AJ, et al: HB-EGF is a potent inducer of tumor growth and angiogenesis. Cancer Res 64: 5283-5290, 2004.

122. Ushiro S, Ono M, Izumi H, Kohno K, Taniguchi N, Higashiyama S and Kuwano M: Heparin-binding epidermal growth factor-like growth factor: p91 activation induction of plasminogen activator/inhibitor, and tubular morphogenesis in human microvascular endothelial cells. Jpn J Cancer Res 87: 68-77, 1996.

123. Vasse M, Pourtau J, Trochon V, et al: Induces angiogenesis in vitro and in vivo. Arterioscler Thromb Vasc Biol 19: 1835-1842, 1999.
124. Huang SP, Wu MS, Shun CT, Wang HP, Lin MT, Kuo ML and Lin JT: Interleukin-6 increases vascular endothelial growth factor and angiogenesis in gastric carcinoma. J Biomed Sci 11: 517-527, 2004.

125. Loeffler S, Fayard B, Weis J and Weissenberger J: Interleukin-6 induces transcriptional activation of vascular endothelial growth factor (VEGF) in astrocytes in vivo and regulates VEGF promoter activity in glioblastoma cells via direct interaction between STAT3 and Spl. Int J Cancer 115: 202-213, 2005.

126. Jee SH, Chu CY, Chiu HC, Huang YL, Tsai WL, Liao YH and Kuo ML: Interleukin-6 induced basic fibroblast growth factordependent angiogenesis in basal cell carcinoma cell line via JAK/STAT3 and PI3-kinase/Akt pathways. J Invest Dermatol 123: 1169-1175, 2004

127.Zumoff B, Strain GW, Miller LK, Rosner W, Senie R, Seres DS and Rosenfeld RS: Plasma free and non-sex-hormone-bindingglobulin-bound testosterone are decreased in obese men in proportion to their degree of obesity. J Clin Endocrinol Metab 71: 929-931, 1990.

128. Isidori AM, Caprio M, Strollo F, Moretti C, Frajese G, Isidori A and Fabbri A: Leptin and androgens in male obesity: evidence for leptin contribution to reduced androgen levels. J Clin Endocrinol Metab 84: 3673-3680, 1999.

129. Ishikawa M, Kitayama J and Nagawa H: Enhanced expression of leptin and leptin receptor (OB-R) in human breast cancer. Clin Cancer Res 10: 4325-4331, 2004. 